\title{
AC 2012-3706: ADAPTATION OF DESIGN MODULES TO FIRST-YEAR ENGINEERING COURSES AND K-12 OUTREACH: UPDATE ON IDEAS PROJECT
}

\section{Ms. Amber Kemppainen, Michigan Technological University}

Amber Kemppainen is a Senior Lecturer in the Engineering Fundamentals Department at Michigan Technological University.

Dr. Gretchen L. Hein, Michigan Technological University

Ruth Archer, Michigan Technological University

Ms. Meral Jackson, Michigan Technological University

Mary A. Fraley

Crystal Lynn Payment, Michigan Technological University

Crystal Payment earned a B.S. in environmental engineering and an M.S. in civil engineering, both from Michigan Technological University, focusing on water resources. She has worked for the Michigan Department of Environmental Quality as a Hydrologic Engineer, as independent consulting in forestry, Summer Youth Programs Instructor at Michigan Technological University, and as an Adjunct Faculty member for the Department of Engineering Fundamentals at Michigan Technological University, Gogebic Community College, and Keweenaw Bay Ojibwa Community College. She currently works as a Hydrologist for the Minnesota Department of Natural Resources. 


\title{
Adaptation of Design Modules to First-Year Engineering Courses and K-12 Outreach - Update on IDEAS Project
}

\begin{abstract}
Students enrolled at Michigan Technological University and are pre-calculus ready follow a three-course sequence through the first-year engineering program (ENG1101, ENG1100, and ENG1102). As part of the NSF Funded IDEAS project (DUE-0836861), design modules were created in biomechanics, wind, and aquaculture for this course sequence ( 200 students). For the biomechanics module, students designed, built, and analyzed a prosthetic leg. Students in the wind turbine module completed and analyzed a lab-scale wind turbine constructed from recycled materials for their first course and used 3-D modeling software to design turbine blades for a second semester project. These blades were printed on a 3-D printer an attached to an existing stand for a performance analysis. In the aquaculture project, students design, built, and analyzed a small-scale aerator for an aquaculture facility. In the second semester, students developed the layout of the facility and evaluated the pumping system currently in place.

The wind turbine and biomechanics modules were implemented as group projects in two summer youth programs (Women in Engineering and the Engineering Scholars Program) in 2011.

Students in these programs had ten hours to construct and analyze their designs. Students looking at the biomechanics module constructed an artificial limb using PVC piping for the "bones" and constructed the knee joint using a variety of materials (hinges, paint rollers, etc). They tested this design in various ways. The first test was to verify that their design had the correct range of motion. They compared measurements from their own legs to the design using a goniometer. The next step was to determine the force exerted during a kick as measured on a force plate and also using a soccer ball. For the wind turbine project, students constructed blades for an existing hub and stand using various materials (plastic bottles, paper maché, cardboard, etc). The turbine performance was measured using a multimeter for the voltage generated and a phototachometer for the turbine RPM.
\end{abstract}

From an IDEAS project overview provided during a faculty workshop in August 2011, the wind energy project was selected by instructors for implementation into ENG1101. Aspects of the project from ENG1001 and ENG1100 were used for this new application. This paper will detail the original design projects, the integration aspects and challenges for modifications to a separate course sequence and the summer youth program, and recommendations for further integration in other applications.

\section{Background}

Traditionally, high school students who are "good at science and math" have been encouraged to go into engineering. Recently, a paradigm shift has occurred. Engineering is being promoted as a career for students that ${ }^{1}$ :

- are creative

- like collaborating with others

- are curious and persistent

- want to make a difference 
- like solving problems or improving processes

In accordance with the old paradigm, traditional engineering education has focused on the fundamentals of engineering and their application to engineering problems. However, recent studies show that engineers need additional skills in order to thrive in the current business environment. Additionally, the old paradigm is often at odds with the interests, socialization and experiences of women and other underrepresented groups ${ }^{2}$. While it is important for engineering education to continue providing a strong technical background, other skills (i.e. communication skills) are becoming increasingly more important. ${ }^{3}$ It has also been shown that the lack of experience in bringing an engineering design concept to a working prototype and poor written communication skills significantly contribute to retention problems. ${ }^{4}$ The importance of data analysis and interpretation, and communication skills in engineering education is outlined in ABET criteria $3 b$ and $3 g^{5}$.

Therefore, the skills students need to succeed in engineering are not only quantitative, but qualitative. Engineering schools need methods to evaluate the development of communication and creative ability. Many schools are incorporating project-based interdisciplinary exercises into their engineering curriculum in order to develop the qualitative and quantitative skills simultaneously. ${ }^{3}$ It has been shown that introducing design in the freshman engineering course has a positive impact on retention, stimulates interest in engineering and enhances communication, teaming and time management skills. ${ }^{6,7,8}$

\section{Introduction}

The first-year engineering courses at Michigan Technological University (Michigan Tech) emphasize hands-on, active learning where student teams work to solve engineering problems. Our first-year curriculum has two paths as shown in Figure 1: one for calculus-ready students (ENG1101 and ENG1102) and one for pre-calculus ready students (ENG1001, ENG1100, and ENG1102). About 75\% of the incoming students are calculus-ready when they arrive on campus. Each of the courses has a heavy design component and students learn about design through the completion of design exercises ranging from a design/build/test process in ENG1001 and ENG1101 to a design/model/test process in ENG1100. The course topics (statistics, ethics, communication, etc) are often tied into the design project to create continuity in the courses. 
Enter Michigan Tech First-Year Engineering Program

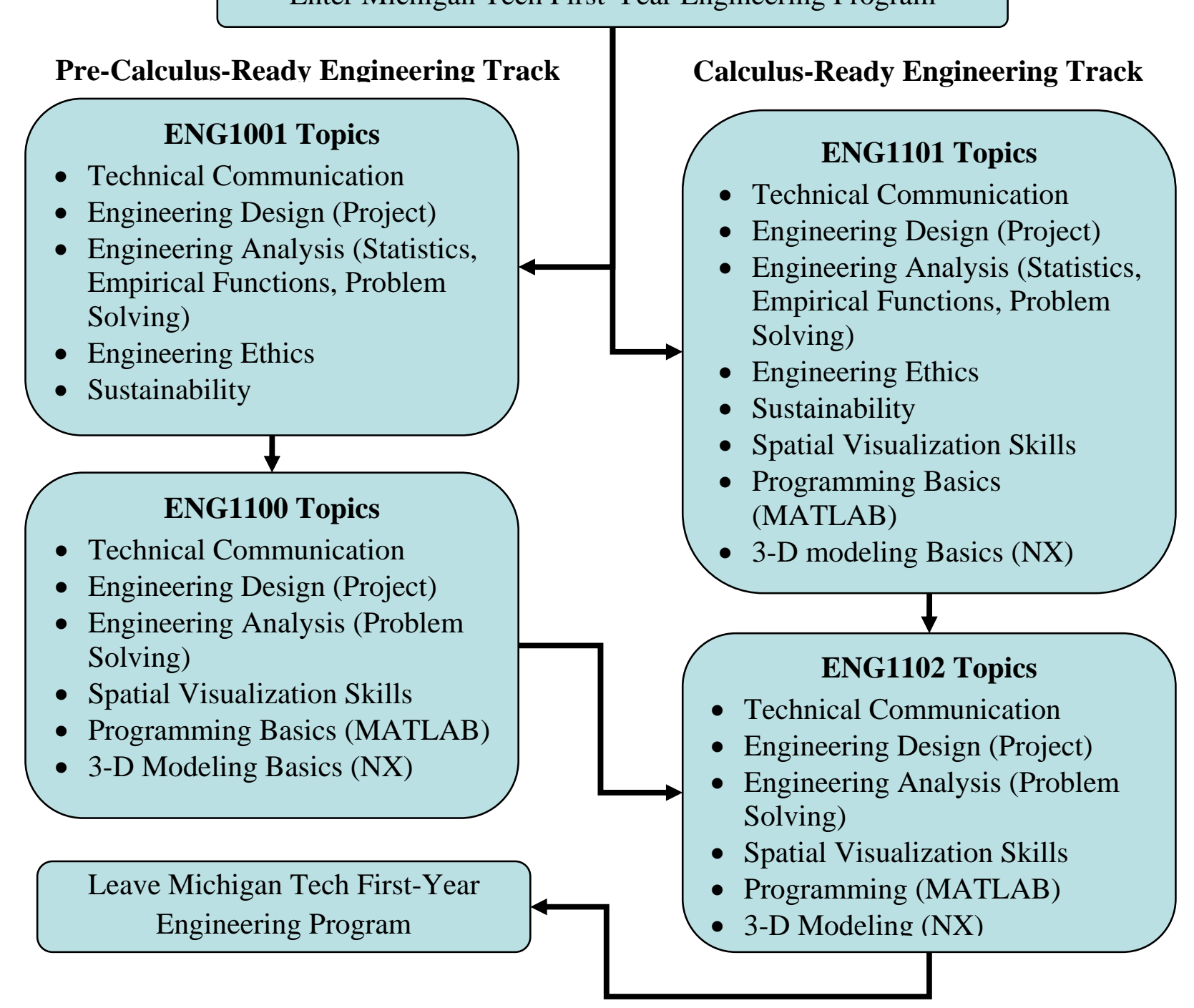

Figure 1. Course Pathways for First-year Engineering Students

Since the fall semester of 2009, students enrolled in the pre-calculus sequence of the first-year engineering program at Michigan Tech participated in the implementation of the Innovation and Design in Engineering for Academic Success (IDEAS) project. The goals of the project were to develop three design modules in aquaculture, biomechanics, and wind energy for first-year engineering classes. The modules were designed to be adaptable for various curriculums and applications; however, they were initially implemented in the pre-calculus ready track of the first-year engineering program at Michigan Tech.

These projects had several desired components as described in Table 1 below. For each module, the data and designs generated in ENG1001 were used again in ENG1100 to reinforce the initial project concepts and create linkages between the two courses. For example, the students would create a physical model of their designs in ENG1001. Using the knowledge and experiences gained from this construction, they would create a 3-D virtual model and program simulation of the design in ENG1100. 
Table 1. IDEAS Module Initial Implementation Plan for ENG1001/1100

\begin{tabular}{|l|ll|}
\hline \multicolumn{1}{|c|}{ ENG1001 } & \multicolumn{1}{c|}{ ENG1100 } \\
\hline 1) $\begin{array}{l}\text { In-Class Module Introduction } \\
\text { (provide students with specific } \\
\text { design goals) }\end{array}$ & 1) $\begin{array}{l}\text { In-Class Module Introduction (provide students } \\
\text { with specific design goals) (or re-introduction from }\end{array}$ \\
2) $\begin{array}{l}\text { Student construction/testing of their } \\
\text { designs. }\end{array}$ & 2) $\begin{array}{l}\text { Student modeling of a portion of their design using } \\
\text { S-D modeling software (NX). }\end{array}$ \\
3) $\begin{array}{l}\text { Student analysis and documentation } \\
\text { of project test data, both individual } \\
\text { teams and class performance. }\end{array}$ & 3) $\begin{array}{l}\text { Student development of a simulation to test their } \\
\text { physical model using MATLAB. }\end{array}$ \\
& 4) $\begin{array}{l}\text { Student comparison of collected (ENG1001) and } \\
\text { simulated (ENG1100) data. }\end{array}$ \\
& 4) Student analysis and documentation of project. \\
\hline
\end{tabular}

To enable the students to complete their project, student teams completed a series of deliverables throughout the semester. Each project began with initial research into the design problem, an evaluation of the teams' subsequent design concepts, and a detailed project management plan. Teams constructed and analyzed their respective designs, researched and summarized the ethics behind their designs, and reported their results in a final design project memo in ENG1001. ${ }^{9}$ In ENG1100, teams built upon their first semester experience, created a new design and analyzed it using simulation software (MATLAB). Their results were reported in a final design project. The project overviews and student products are described below for each of the three modules.

\section{Aquaculture Module}

This module focused on the evaluation of a recirculating aquaculture system (RAS). During their first semester (ENG1001), students designed an aeration system for 10,000 - 50,000 fish. As shown in Figure 2, they designed, built, and tested a lab-scale aerator. Using a spreadsheet, they analyzed the oxygen consumption in the RAS by fish respiration, food consumption, and waste decomposition to determine the number of aerators needed for the various sized facilities. Comparing their aerator performance to the other teams in their section allowed them to report on the effectiveness of their designs.
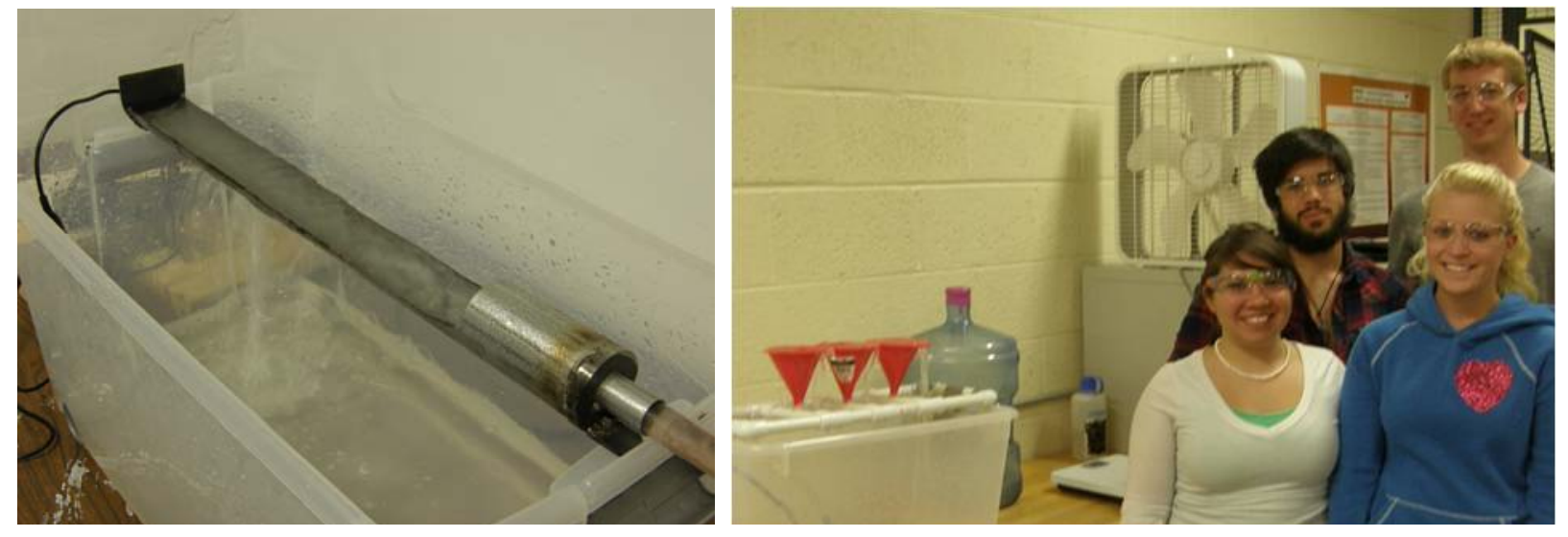

Figure 2. ENG1001 Student Aerator Designs

In their second semester (ENG1100), students designed the RAS facility layout and evaluated the 
recirculating pump system. The pumps for the project were provided and students were able to measure the flowrate of the pump for various height tanks and use the data to size their facility. They designed a new impeller for the pump using NX, printed it using a rapid-prototype machine, and testedtheir design to see if it improved the performance of their facility. ${ }^{10}$ Teams used their pump impeller data to predict the ideal height of fish tanks, determine the maximum number of fish, monitor fish growth of the fish given a constant amount of feed, and output the operating costs of the facility using a MATLAB simulation. Students were challenged to include an automatic feeding system in their program and determine the performance. They reported their overall project results in a final project report.

\section{Biomechanics Module}

For the biomechanics module, ENG1001 students designed, built, and tested an artificial leg. They used a force plate to determine the force generated by a simple kicking motion and analyzed the component forces using a spreadsheet. As shown in Figure 3, the majority of student teams had a simplified physical model due to project constraints (cost, material availability) and scope of the class.

Overall, students were excited by the idea of this project, but the project constraints limited the design and use of the leg. While students liked the human-related aspects and the class activities related to human motion and mechanics, their projects were simplistic and little effort was put into analyzing the project data. They enjoyed constructing the leg and would like to see similar projects in the future, but they were not able to use the data they collected to analyze the model. From this feedback, the instructors felt that this project would fit better in ENG1102, the terminal first-year engineering course because students possess the analytical and background skills to analyze this complex model. Alternatively, as shown later with the summer youth programs, the focus could be solely on the design-build-test process, eliminating the complex mathematical analysis. Because of the results of this ENG1001 module, this project was not used in ENG1100.

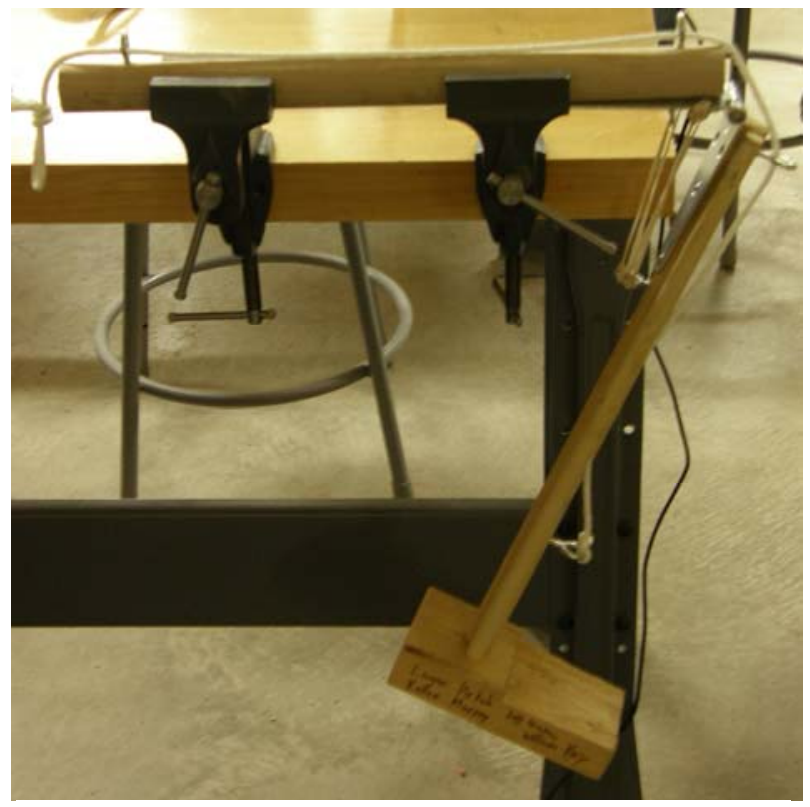

Figure 3. ENG1001 Student Prosthetic Limb Design

\section{Wind Energy Module}

In ENG1001, students designed, constructed, tested and analyzed a lab-scale horizontal axis wind turbine (HAWT). Since the testing was completed in the first-year engineering learning center, the "wind” was generated by a three speed box fan. Students measured the turbine's revolutions per minute (RPM) using a photo tachometer and the wind velocity using an anemometer. The data collected was used in spreadsheet calculations to find their turbine's potential power generation. After analyzing their team's data, they repeated the calculations for 
the class turbine data to compare turbine performances from all teams. Figure 4 shows an example wind turbine testing from a Fall 2011 ENG1001 team.

During ENG1100, students designed and evaluated a new blade configuration for an existing HAWT tower. Teams designed their blades using NX modeling software, printed them using a rapid-prototype machine, and tested their new blade design. They used a motion detector to record the blade rotation during testing and analyzed their data using MATLAB to find the turbine blade RPM. They completed their analysis by "scaling

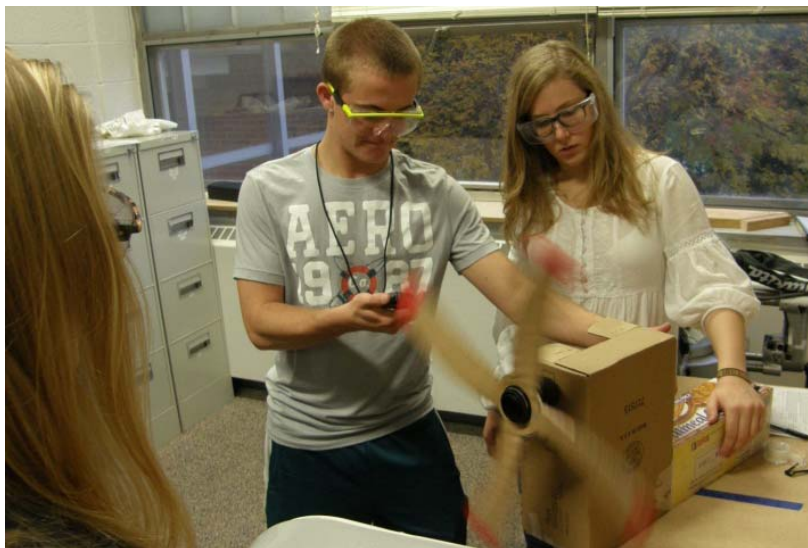

Figure 4. ENG1001 Student Wind Turbine Design up" their model in the simulations to determine power production and costs.

\section{Adaptation of Wind Energy to ENG1101}

In August 2011, the co-PIs from the IDEAS project hosted a workshop to introduce the project modules to the first-year engineering faculty and instructors. The workshop covered the aquaculture and wind turbine projects from ENG1001/ENG1100 and provided implementation recommendations for ENG1101. As a result of the workshop, three instructors incorporated the Wind Energy Module into seven sections (out of 12) of ENG1101 ( 350 students out of 600). The general deliverables for the ENG1001, ENG1100, and ENG1101 projects are listed below in Table 2. Most of the necessary adaptations involved integrating and combining the design activities from the two-course sequence into a single course.

Like in ENG1001, students completing this modified project designed and constructed lab-scale HAWT and support structure, but followed the pre/post testing and analysis procedure from ENG1100 (Table 2). Students used the data from their wind turbine testing as input to a MATLAB simulation program. The NX component associated with ENG1100 could not be completed due to when NX was covered in ENG1101. Some of the sections of ENG1101 also incorporated ethical analysis into the design process.

As the modules were designed to be adaptable, each instructor was able to customize the project to meet their course needs. Therefore, in order to assess this adaptation and implementation of the Wind Energy Module into ENG1101, the instructors completed a short project evaluation which is summarized below.

\section{Overall ENG1101 Project}

As shown in Table 2, the components used from ENG1001, were the initial research and project management, design construction, design pre-testing and testing, and the final report. Two of the three instructors did require students complete an integrated design project ethical analysis. The remaining instructor included engineering ethics via traditional case study analysis. The ethics analysis identified cultural and environmental concerns when utilizing wind energy based on a University of Massachusetts-Amherst Renewable Energy Resource Laboratory fact sheet. ${ }^{11}$ 
Student teams debated their chosen ethical issues using a RESOLVEDD analysis and reported their analysis via a memo to the instructor. ${ }^{12}$ The ENG1001 component of the class data analysis was not integrated into ENG1101. The elimination of this component permitted the inclusion of the ENG1100 MATLAB mathematical model into the ENG1101 project.

Table 2. Wind Turbine Design Project Deliverables for Pre-Calculus-Ready Track of FirstYear Engineering Program (ENG1001/ENG1100) and Adaptations to Calculus-Ready Track (ENG1101)

\begin{tabular}{|c|c|c|}
\hline \multicolumn{3}{|c|}{ Design Project Activities } \\
\hline ENG1001 & ENG1100 & ENG1101 \\
\hline $\begin{array}{l}\text { 1. Initial Research and } \\
\text { Project } \\
\text { Management plan } \\
\text { 2. Design } \\
\text { Construction } \\
\text { 3. Pre-test Designs } \\
\text { 4. Design Updates } \\
\text { 5. Design Testing } \\
\text { 6. Team Data Analysis } \\
\text { 7. Design Ethics } \\
\text { Analysis } \\
\text { 8. Class Data Analysis } \\
\text { 9. Final Report Memo }\end{array}$ & $\begin{array}{ll}\text { 1. } & \text { Project } \\
\text { Management Plan } \\
\text { 2. NX Blade Design } \\
\text { 3. Design Testing } \\
\text { 4. Math Model } \\
\text { 5. Final Design } \\
\text { Report }\end{array}$ & $\begin{array}{l}\text { 1. Initial Research and } \\
\text { Project Management plan } \\
\text { 2. Design Construction } \\
\text { 3. Pre-test Designs } \\
\text { 4. Design Testing } \\
\text { 5. Math Model } \\
\text { 6. Design Ethics Analysis } \\
\text { (varied participation) } \\
\text { 7. Final Report }\end{array}$ \\
\hline
\end{tabular}

\section{Integrated in-class design project activities}

A key aspect of the ENG1001/1100 design modules was to integrate the design project throughout the class activities. For key components of the course (unit conversions, spreadsheet calculations, engineering ethics, etc.), the course materials were adapted to include aspects of the design modules. For example, when unit conversions were covered in the class, students learned about wind turbine power and how use unit conversions when completing these calculations. As shown previously, engineering ethics was integrated into the ENG1001 design process. Therefore, students researched and documented various ethical issues associated with wind energy. Due to the course structure of ENG1101, the instructors had fewer opportunities to integrate the design project throughout the course. The instructors were able to include the project overview and days to work on the mathematical model. Additionally, two of the instructors integrated the ethics of wind energy into the engineering ethics portion of the course.

\section{Implementation Challenges}

Overall, the ENG1101 instructors felt the implementation of the wind energy design project into ENG1101 went well. Two of the three instructors would like to see data generated that could be used to find an empirical function to describe wind energy data. This would be difficult because it would involve using a small wind tunnel to make measurements at the beginning of the semester. Currently, there is no small wind tunnel constructed. The advantage would be that 
students would use the data and function twice within the semester; once when determining the function and a second time in their mathematical mode.

All the instructors wanted to more fully integrate the design project throughout the course material. They did note that this would be difficult because this project is one of several used in a given semester in ENG1101. One instructor noted:

"The inability to incorporate additional wind turbine examples into homework or in-class examples was frustrating in that being able to incorporate the class design project into everyday exercises would provide continuity to a class which covers numerous topics in a limited period of time. At times, ENG1101 can feel disjointed as the progression of topics seems to abruptly end after one subject then begin a different subject with little or no transition. For example, it can be difficult to transition from unit conversions to statistics to MATLAB programming since they are seemingly unrelated subjects. The ability to use a single theme of wind energy through the semester might make the transition easier. There is little room in the current ENG1101 class material to incorporate wind energy into all or most of the lectures. One of the strengths of the ENG1001 class (I feel) is the continuity in the class provided by integration of the semester design project into much of the class material.”

Additional design criteria are needed to limit student costs, and the use of "pinwheels" or other prefabricated turbine blades. Student designs should have a minimum efficiency such that the electronic recording device can capture the RPMs. When students designed inefficient (slowly rotating blades) designs, the electronic monitoring device was unable to capture the revolutions.

\section{Overall Adaptability of the Wind Energy Project and Assessment}

All instructors commented that the students enjoyed the hands-on nature of the wind energy project. The implementation of a "real-world" project was an additional aspect that the students liked. Students in ENG1001 and ENG1101 were surveyed to assess their perceptions of the wind design module. The overall results are shown in Table 3. Overall, students in ENG1101 rated the project higher than students in ENG1001 except with regard to the challenging nature of the project. The lower ratings in ENG1001 could be due to the different skill set of the students. Most of the ENG1001 students have little or no background in using spreadsheets. Many have not used computer software to analyze problems. In contrast, the opposite is true for the ENG1101 students. They have a much more inclusive skill set when entering the university. Therefore, their ability to complete the work and understand its applicability was expected to be higher.

For both classes, the students did not find the engineering aspects of the design project challenging, but they did have some challenges using the test data to analyze the project. This conflict in feedback could be due to how students interpreting "engineering aspects" as the design, construction and testing of the HAWT. It was not difficult for students to complete the construction and testing phase of the project. First-year students may not think that analyzing and utilizing their data are "engineering aspects"; because based on their responses, they did find using their test data in simulations or spreadsheets to be more challenging. The majority of students in ENG1101 were able to see the limitations of the project and use the information from 
class in their design. Students liked building all the wind turbines and teams felt they would like to see more of this type of project in the future. The ENG1001 students did value the fully integrated design module (course topics and assignments were integrated with the design project) as shown in question seven. ENG1101 students did not rate this aspect as high which is probably because course topics were not fully integrated with their design project.

Table 3. Student Evaluation of Wind Energy Module Adaptation

\begin{tabular}{|l|c|c|c|}
\hline \multirow{2}{*}{\multicolumn{1}{|c|}{ Likert Scale Question }} & \multicolumn{2}{|c|}{ Percent of Student Agreement with Statement } \\
\cline { 2 - 4 } & $\begin{array}{c}\text { ENG1101 } \\
\text { Instructor 1 } \\
\text { (n=79) }\end{array}$ & $\begin{array}{c}\text { ENG1101 } \\
\text { Instructor 2 } \\
\text { (n=36) }\end{array}$ & $\begin{array}{c}\text { ENG1001 } \\
\text { (n=36) }\end{array}$ \\
\hline $\begin{array}{l}\text { 1. I can clearly see the engineering } \\
\text { application of our design project. }\end{array}$ & $87.3 \%$ & $77.8 \%$ & $66.7 \%$ \\
\hline $\begin{array}{l}\text { 2. The engineering aspects of the design } \\
\text { project were challenging. }\end{array}$ & $58.2 \%$ & $38.9 \%$ & $58.3 \%$ \\
\hline $\begin{array}{l}\text { 3. The design project used skills we } \\
\text { learned in our engineering class. }\end{array}$ & $79.7 \%$ & $80.6 \%$ & $72.2 \%$ \\
\hline $\begin{array}{l}\text { 4. I understood the limitations of the } \\
\text { design after doing the project testing in } \\
\text { the learning center. }\end{array}$ & $83.5 \%$ & $80.6 \%$ & $77.8 \%$ \\
\hline $\begin{array}{l}\text { 5. I was able to easily use the testing } \\
\text { information to analyze the project. }\end{array}$ & $75.9 \%$ & $72.2 \%$ & $55.6 \%$ \\
\hline $\begin{array}{l}\text { 6. I liked designing our wind turbine. } \\
\text { 7. I would like to see more interactive } \\
\text { design projects in the first-year } \\
\text { engineering courses that combine } \\
\text { physical testing, modeling, and design. }\end{array}$ & $81.0 \%$ & $80.6 \%$ & $77.8 \%$ \\
\hline
\end{tabular}

*agreement responses were assessed using a 5-point Likert-type scale

\section{Adaptation of the IDEAS Modules for Student Outreach}

At Michigan Tech, there are several summer youth programs that have engineering group project components. The Engineering Scholars Program (ESP) is a weeklong investigation of engineering careers in areas such as mechanical, computer, environmental, electrical, chemical, biomedical, civil, geological, materials, and related disciplines. This program is a highly competitive scholarship program which provides a chance for traditionally underrepresented high school freshmen, sophomores, and juniors the opportunity to investigate careers in engineering and science. In 2011, 90\% of the program's 140 participants could not have attended without a scholarship. Of the participants, 27\% were female, 17\% African American, and 18\% of other non-Caucasian ethnic identities. The Women in Engineering (WIE) program is similar to the ESP, but oriented toward female high school students. In 2011, 89\% of the program's 121 students could not have participated without a scholarship. Participants were $100 \%$ female, and $17 \%$ belonged to non-Caucasian ethnic groups. The programs allocate 10 hours over the 5 day program to a group project component where the students to research, design, build, and test 
their designs. The biomechanics and wind energy modules were adapted for these two programs where 24 students in each program participated (48 total students).

\section{Summer Youth Wind Turbine Project}

The 2011 Summer Youth Wind Turbine project focused on creating a HAWT or Vertical Axis Wind Turbine (VAWT) and measuring the resulting RPMs. In this case, students designed and created the blade configuration for an existing hub and stand. During the first session, the students were introduced to the basic concepts and design choices for a HAWT. A short presentation and on-line research conducted by the students were their main sources of background information. To emphasize the design aspect of engineering, students were encouraged to research, sketch, and plan, their blade design before construction was initiated.

The second session focused on completing design sketches, then beginning construction. Student teams were supplied with assorted grades of cardboard, construction paper, $1 / 4$ " wooden dowel rods, glue, and drawing materials (markers, pens, paint, glitter, etc.). Based on their design sketches, they began construction of their wind turbine blades with the intent to maximize the measured RPM's of the wind turbine when placed three feet from a box fan. Figures 5 and 6 below show an example of turbine blade design and the testing set-up.

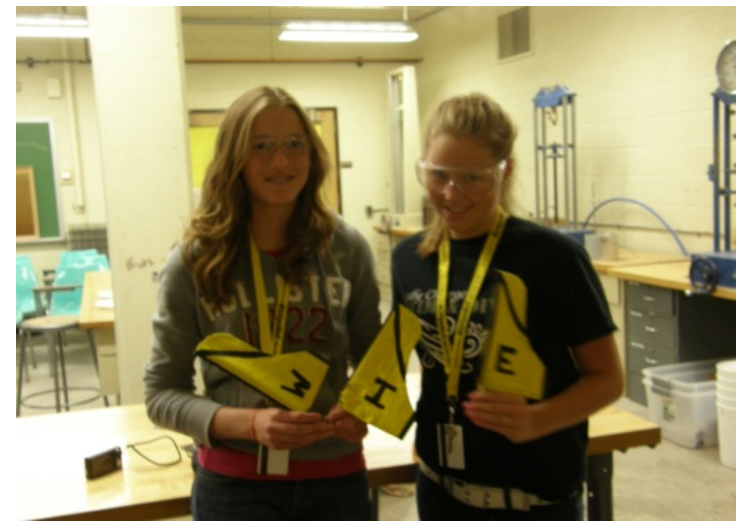

Figure 5. Wind Turbine Blade Design Example Summer 2011

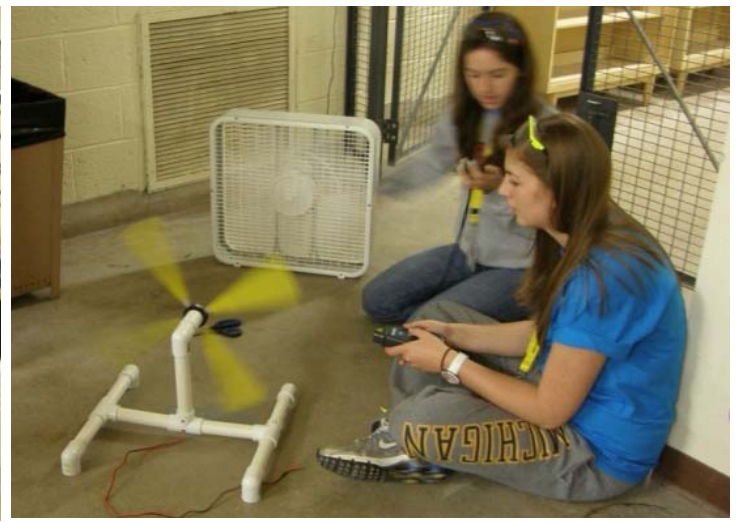

Figure 6. Wind Turbine Testing Set-up

During the third and fourth sessions, construction continued with the completion of the wind turbines blades, and some pre-testing. At the Friday session, students measured the RPMs of their turbines using a phototachometer. The students learned different methods and sources for researching wind turbine design, the purpose of wind turbines in sustainability and energy production, designing/sketching an idea and turning it into a prototype, and re-designing or changing initial configurations. During the testing process, students saw how changing the blade angle affected the RPMs and that that different blade configurations (2-blade, 3-blade, 4-blade, and 6-blade HAWT, or a VAWT) could produce higher or more consistent RPMs.

\section{Summer Youth Biomechanics Project}

Like previously described, the biomechanics project involved the design and construction of an artificial leg that would kick against a force plate. Since constructing a simulated limb involved 
the use of tools, students received not only an introduction to the biomechanics project on the first day, but also the safety requirements of the laboratory, including proper usage of safety glasses and the tools. Students were provided with lengths of PVC piping for the leg bones and they were responsible for designing and testing the knee joint. The students measured of their knee joints using goniometers to determine the average range of motion before beginning design sketches. Students started rough sketches of their set-up and decided which materials would work best.

On the second day, student teams with a \$5.00 limit went to a local hardware store where the staff assisted the students in finding and selecting their design materials. Some of the materials chosen by the students included smaller paint rollers (for the knee joint), a ball-and-hinge system utilizing a toilet float and 2-Liter pop bottle, hinges and screws, clear hose, zip ties, and bungee cords. For many of the students, it was their first time to a hardware store, and they thoroughly enjoyed the experience.

During the third and fourth days, students constructed the limbs and completed preliminary testing. Students used the tools provided to construct their legs, and goniometers to measure the leg extension angle. During the construction process, many teams updated and improved on their initial design idea. Instructors emphasized the engineering process. Students tested their designs by measuring the force of kick generated by the leg against a force plate. Some teams found that their knee joint construction was not strong enough to support a 15-lb weight and/or the foot of the leg failed upon impacting the force plate or did not register as a force on the forceplate. Additionally, the student designs kicked a soccer ball from a stand. This testing was the favorite trial for the students participating.

All students enjoyed constructing the prosthetic leg (shown in Figures 7 and 8). Many of the participants shared that they had specifically selected this project, and would recommend it to future participants. During the Summer Youth Student Showcase, this project was one of the most popular for the other students and visitors. Many of the students were proud of their designs because they specifically brought their parents to see them.

\section{Conclusions}

Three design modules, wind energy, aquaculture and biomechanics were developed and implemented into a first-year engineering program. The initial projects were piloted in a twocourse sequence, and later adapted to inclusion into a single first-year course and high school summer outreach programs. Regardless of where the modules were implemented, the students enjoyed them. They liked completing a real-world design project. They realized the value of using data they generated in analyzing the system performance, although they found the transition from generating data to analyzing data to be challenging. The successful implementation of the projects into a different engineering course and summer outreach programs illustrates the transportability of the projects for different universities and programs.

As the program continues and more instructors include the project in their courses, the projects and their effectiveness will be evaluated with respect to student learning and motivation. Similar analyses will be completed for the Summer Youth Program activities. Due to the success of the Wind Energy and Biomechanics projects, they were included in the Michigan Tech 
MindTrekkers program. These projects were showcased the $2^{\text {nd }}$ USA Science and Engineering Festival in Washington, DC, April 28-29, 2012.

\section{Acknowledgements}

This material is based upon work supported by the National Science Foundation under Grant No. 0836861. The authors thank the first-year engineering students for their participation in these projects.

\section{Bibliography}

1. "Engineer Your Life: A Guide to Engineering for High School Girls” WGBH Educational Foundation and National Academy of Engineering in Partnership with Extraordinary Women Engineers Coalition. (www.engineeryourlife.org) Web Accessed April 28, 2008.

2. Goodman Research Group, Inc. 2002. Final Report of the Women's Experiences in College Engineering (WECE) Project. Funded as "A Comprehensive Evaluation of Women in Engineering Programs.” National Science Foundation Grand REC 9725521, Alfred P. Sloan Foundation Grant 6-1016. Cambridge, MA.

3. Ogando, J., “Teaching the New Engineering Skills.” Design News. Vol. 63 No. 4 pg 59.

4. Pomalaza-Raez, C., Groff, B., "Retention 101: Where Robots Go...Students Follow,” Journal of Engineering Education. January 2003 (http://www.asee.org/publications/jee/).

5. ABET, Inc (Accreditation Board for Engineering and Technology) (http://www.abet.org) Web Accessed May 2008.

6. Karl, R., Muraleetharam, K., Mooney, M., Vieux, B.E., "Sooner City Design across curriculum” Journal of Engineering Education, 2000, 89 (1): 79-87 (http://www.asee.org/publications/jee/).

7. Parker, P., Anderson, M. "Assessment of a First year introduction to a civil and environmental engineering course.” Proceedings of the 2004 American Society for Engineering Education Annual Conference \& Exposition (http://asee.org/conferences).

8. Rowe, C., Mahadevan-Jansen, A. "Module-based Freshmen engineering course Development." Proceedings of the 2004 American Society for Engineering Education Annual Conference \& Exposition (http://asee.org/conferences).

9. Hein, G. L., Kemppainen, A. J., Amato-Henderson, S. L. "First-Year Engineering Students and Ethical Analysis", ASEE Annual Conference. www.asee.org. Vancouver, BC, Canada, June 26-29, 2011.

10. Kemppainen, A. J., Jeason, N., Hein, G. L. "Modifying a Pumping System in a First-Year Engineering Design Project", ASEE Engineering Design Graphics Division. www.edgd.asee.org. Houghton, MI, October 3-6, 2010.

11. "Wind Power: Impacts and Issues" http://www.umass.edu/windenergy/publications/published/communityWindFactSheets/RERL_Fact_Sheet3_I mpacts\&Issues.pdf. Web Accessed January 12, 2012.

12. Pfeiffer and Forsberg. Ethics on the Job: Cases and Strategies, 3rd Edition, 2005. 